\title{
"Chuang Tze e o rei de Chu": Silva Mendes e sua adaptação dos clássicos taoistas
}

\author{
Erasto Santos Crur.
}

\begin{abstract}
Resumo: Este artigo tem como objetivo apresentar a obra Excerptos de Filosofia Taoista do autor Manuel da Silva Mendes, considerado o primeiro português a estudar e divulgar a tradição taoista chinesa, e através da análise do poema: "Chuang Tze e o rei de Chu", demonstrar que este se trata de uma adaptação de um trecho do livro clássico do pensamento chinês Nán Huá Jing (南華經), de Zhuāngそ̌̌ (莊子), e para se atingir este fim, será feita uma análise comparativa com o original em chinês clássico e com a tradução para o inglếs do sinólogo escocês James Legge.
\end{abstract}

\begin{abstract}
This article aims to introduce the work Excerptos de Filosofia Taoista by Manuel da Silva Mendes, whom is considered to be the first Portuguese to study and disseminate the Chinese Taoist tradition. By analyzing the poem: Chuang Tze e o rei de Chu, the present article claims that this poem is an adaptation of the classic book of Chinese thought's stretch Nán Huá Jing (南華經), by Zhuāngž̌ (莊子). To this end, will be made a comparative analysis between the original poem in classical Chinese and the English translation by the Scottish sinologist James Legge.
\end{abstract}

Palavras-chave: Silva Mendes, Literatura de Macau em Lingua Portuguesa, Sinologia, Taoismo, Zhuāngף̌̌

\section{O Taoismo}

É difícil falar de algo tão abrangente como o Taoismo de forma resumida, mas generalizando, podemos dizer se tratar de uma antiga tradição chinesa baseada no Dào (道), caractere que pode ser traduzido como Via Espiritual ou Caminho. Consiste em harmonizar o ser humano e a natureza através do wúwéi (無為) não-ação, que seria basicamente o agir sem subjetivação, o fluir natural 
das coisas, pois uma forte crença desta tradição é de que tudo na natureza está em conexão. ${ }^{1}$

Possui como conceito principal o yìn-yáng (陰陽), pensamento desenvolvido pelos antigos chineses sobre o ciclo e a harmonização da natureza. Para Marcel Granet, yīn-yáng expressam: "[...] aspectos antitéticos e concretos do Tempo. Expressam também aspectos antitéticos e concretos do Espaço."2 Neste conceito, um oposto depende do outro para existir, por exemplo: não haveria noite sem dia, nem alto sem baixo etc. O símbolo do yinn-yáng, chamado taijí (太極), é constituído por duas metades que giram em um ciclo eterno, onde yin (princípio feminino, a noite, a morte) depende de yáng (princípio masculino, o dia, a vida) para manter o ciclo, sendo que ambos possuem o mesmo valor e importância. ${ }^{3}$ Assim como explica Livia Kohn em seu livro Daoism and Chinese Culture, o conceito de bem e mal não existe neste pensamento, pois um necessita do outro em uma relação de coexistência. (2012, p. 21) Para James Miller, este símbolo representa um monte com um lado nas sombras e outro ensolarado, e o lado exposto ao sol durante o dia, passa à escuridão à noite, e vice-versa. Esta alternância serve para mostrar que nada permanece inalterado, ou seja, que tudo no mundo está em constante mudança. ${ }^{4}$

Dois são os livros considerados cânones do Taoismo: o Dào Dé Jing (道德 經) de Lăozǐ (老子), supostamente escrito no sec. V a.C e composto por oitenta e um poemas que tratam dos conceitos do Dào (道), e o Nán Huá Jing (南華經), obra mais conhecida como Zhuāngzì (莊子)", que também é o nome de seu autor, escrito no sec. III a.C. e também discorre sobre o Dào (道), mas este, escrito em prosa e composto por historietas que se utilizam de personagens históricos e lendários para se aproximar do conhecimento popular e facilitar o entendimento dos leitores da época.

\section{O Autor}

Manuel da Silva Mendes (1867-1931), nasceu em São Miguel das Aves, distrito do Porto. Formado em direito pela Universidade de Coimbra, declarava-

1 Para saber mais sobre Taoismo, ver: CHERNG, Wu Jyh. Iniciação ao Taoismo. Rio de Janeiro: Mauad, 2000. V. 1. Ver também: LAOZI. Dao De Jing [Tao Te King]. Tradução de Mario Bruno Sproviero. São Paulo: Hedra, 2007.

2 GRANET, Marcel. O Pensamento Chinês, p. 84. Tradução de Vera Ribeiro. Rio de Janeiro: Contraponto, 1997.

3 Para saber mais sobre yin e yang, ver: ROBINET, Isabelle. Taoism: Growth of a Religion. Translated by Phyllis Brooks. Stanford: Stanforf University Press, 1997. Ver também: SCHIPPER, Kristofer. The Taoist Body. Translated by Karen C. Duval. California: University of California Press, 1993.

4 MILLER, James. Daoism: A Beginner's Guide, p. 53. Oxford: Oneworld Publications, 2008. 
-se anarquista e militou a favor da instauração da república em Portugal. Foi para Macau em 1901 para ocupar o cargo de professor do Liceu, ministrando nas cadeiras de português e latim. Posteriormente, ocupou outros cargos de destaque, como Presidente do Leal Senado, Administrador do Conselho, Reitor do Liceu de Macau, Juiz de Direito, Procurador da República e advogado.

Homem multifacetado, teve trabalhos produzidos em diversas áreas, destacando-se o livro Socialismo Libertário on Anarchismo: História e Doutrina, de 1896. Era um admirador e conhecedor de arte chinesa, publicando vários artigos sobre este tema no jornal macaense $O$ Progresso. Participava ativamente da vida política de Macau, publicando várias críticas à administração portuguesa em periódicos.

Em meio a seus estudos sobre a cultura chinesa, apaixonou-se pelo Taoismo, chegando a publicar duas obras sobre o assunto: Lao-tse e sua doutrina segundo o Tao Te King, de 1909, e o já citado Excerptos de Filosofia Taoista, de 1930, tendo escrito também vários outros estudos dispersos em revistas e jornais. Morre em Macau em 1931.

\section{Excerptos de Filosofia Taoista: Estudo ou Reescrita?}

A obra é dividida em duas partes. A primeira constituída de nove poemas longos, todos baseados nos dois livros clássicos chineses, o Dào Dé Jing (道德經) de Lăož (老子), e o Nán Huá Jing (南華經) de Zhuāngž̀ (莊子), mantendo uma referência maior, aproximadamente setenta por cento segundo o próprio Silva Mendes, com este último. A segunda parte contém trinta pequenos excertos que o autor intitula de Máximas, pensamentos e provérbios, os quais também são baseados no pensamento taoista.

Durante a leitura, podemos ter a impressão de estarmos diante de uma tradução livre de trechos do Dào Dé Jing e do Nán Huá Jing, pois os poemas mantêm uma relação de significados muito grande com os textos originais. Mas apesar desse caráter de tradução, Silva Mendes faz questão de afirmar no capítulo Advertência que “[...] não são trechos traduzidos do 'Tao Teh King' de Lao Tze nem do 'Nan Hua King’ de Chuang Tze.” (MENDES, 1963, p. 275).

Pare reforçar esta afirmação, o autor se utiliza da explicação de que, sendo o Taoismo uma tradição muito antiga, vários autores se utilizaram em larga escala das mesmas expressões, pois teria “[...] fórmas de dizer consagradas, que todos os escritores empregam, de significado preciso e, por isso, de emprego por assim dizer obrigatório; e em grave risco de estabelecer confusão ou de se mostrar pretencioso 
incorrerá quem ousar substituí-las." (Ibid), e ainda complementa que, mesmo no Dào Dé Jing de Lăožl, suposto patriarca deste pensamento, não é possível garantir que todas as frases e expressões presentes no livro são de sua autoria ou se teriam vindo de épocas mais remotas.

António Aresta ${ }^{5}$ descreve as duas obras do autor sobre o Taoismo da seguinte maneira:

Silva Mendes dedicou dois estudos, editados em livro, à filosofia taoista, para além de numerosos artigos dispersos em revistas e em jornais. O primeiro intitula-se Lao Tre e a sua Doutrina Segundo o Tao-Te-King, de 1909, que teve como origem uma conferência que pronunciou no Grémio Militar de Macau.

$[\ldots]$

O segundo estudo, Excerptos de Filosofia Taoista (segundo o Tao-Te- King de Lao Tze e o Nan Hua King de Chuang Tze), data de 1930 e é apenas a primeira parte. É uma obra profundamente original e fruto de um pensamento maduro. (ARESTA, 2002, p. 1365)

Portanto, seja pela influência das próprias palavras de Silva Mendes na $A d$ vertência ou pela falta de um estudo da tradução e adaptação por parte dos críticos e pesquisadores que o estudaram, Excerptos de Filosofia Taoista, apesar de fazer clara referência a alguns trechos do Dào Dé Jing e do Nán Huá Jing e de possuir uma estrutura textual bem diferente da de uma conferência, é comumente colocado ao lado de Lao Tze e a sua Doutrina Segundo o Tao-Te-King e considerado apenas como mais um estudo sobre o Taoismo, e por consequência, sua intertextualidade com as duas obras taoistas não é muito explorada.

Mas mesmo com a afirmação de que não se trata de uma tradução, Silva Mendes também não nega a grande proximidade que seus Excerptos têm dos dois clássicos chineses, principalmente porque sua intenção é declaradamente a de facilitar o entendimento da leitura destes livros aos leitores portugueses. Isso devido ao fato de considerar que as traduções da época, como as do sinólogo escocês James Legge, por exemplo, não expressavam de forma adequada o conteúdo dos textos originais, pois em sua visão, o chinês clássico seria “[...] incompatível com a forma arredondada e larga de dizer europeia” (MENDES, 1963, p. 277). Importante salientar que a crítica de Silva Mendes não era em relação às traduções em si, pois as considerava de uma vasta erudição, mas, sim, o fato de tentarem traduzir 
textos tão complicados literalmente. O autor não era contra traduções literais, mas considerava que estas não propiciavam a compreensão dos conceitos básicos para se conseguir entender as obras, servindo apenas para aqueles leitores que já tinham conhecimentos prévios acerca da cultura chinesa e do Taoismo. Portanto, mesmo usando como ponto de partida o fato de não considerar as traduções da época representativas para escrever os seus Excerptos, o próprio Silva Mendes vê sua obra como uma espécie de estudo interpretativo do Dào Dé jing e do Nán Huá Jing. Mas será que apenas a afirmação de que "não se trata de uma tradução [...]" é o suficiente para a obra não ser classificada como tal, mesmo que seu conteúdo possa provar o contrário? Tal observação acaba por estimular um embate entre o que o autor afirma e o que evidencia o conteúdo de sua obra.

\section{Tradução ou Adaptação?}

Entre tradução e adaptação há muitas discussões teóricas. Vários conceitos foram utilizados em diversas épocas, mas assim como mostra Lauro Maia Amorim em Traducão e Adaptação: Encruzilhadas da textualidade em Alice no País das Maravilhas, de Lewis Carrol, e Kim, de Rudyard Kipling, até os dias de hoje não se tem uma descrição precisa do que pode ser considerado tradução ou adaptação. (2005, p. 40-41)

Durante os anos, vários teóricos da tradução criaram categorias a fim de melhor definir as diversas características de diferentes tipos de tradução. Muitas destas categorias não são completamente aceitas, possuindo várias brechas que acabam sendo exploradas por outros teóricos. ${ }^{6}$ José Pinheiro de Souza em seu artigo Teorias da Tradução: Uma Visão Integrada trata da dicotomia tradução literal versus tradução livre (1998, p. 51-52), que de um modo geral, podemos definir respectivamente como:

1) Processo cujo o objetivo é fornecer o conteúdo do original da forma mais fiel possível, tentando reproduzir até mesmo a equivalência de palavras e a semântica da língua fonte para a língua meta. É a chamada tradução literal ou palavra-a-palavra;

2) Processo que tem como base a transferência de mensagens, conteúdos ou significados do original entre a língua fonte para a língua meta. Este tipo é

6 Para saber mais sobre teorias da tradução, ver: MILTON, John. Tradução, Teoria e Prática. São Paulo: Martins Fontes, 1998. Ver também: VENUTI, Lawrence. The Translator's Invisibility: A bistory of translation. London and New York: Routledge, 1995. 
mais aberto, pois considera como aspecto mais importante a passagem da informação e do sentido, não sendo necessária a literaridade para se conseguir este fim. Este processo também é conhecido como tradução livre, e em muitas das teorizações sobre a tradução, a adaptação se encaixaria neste tipo. ${ }^{7}$

Tomando como base a explicação de Amorim (2005, p. 48), podemos dizer que, enquanto a tradução literal é considerada por muitos como um trabalho mais erudito, pois demanda do tradutor uma reescrita ao mesmo tempo fiel ao original e legível à língua meta, o que lhe confere um status de exímio conhecedor da língua fonte caso sua tradução seja bem sucedida, a adaptação é muitas vezes rotulada como transgressora, pois seu processo acarretaria na violação do texto original, muitas vezes diminuindo-o em grandes proporções, ou modificando aspectos que os seguidores das traduções literais repudiam. Entretanto, ainda segundo Amorim, no que concerne aos direitos autorais, os tradutores geralmente ficam para trás, uma vez que seu trabalho é considerado como uma espécie de "reprodução do texto original" (Ibid), ao passo que os adaptadores, por terem um processo de criatividade ao realizarem suas adaptações, muitas vezes recebem os direitos autorais de suas reescritas.

Ainda falando sobre o contraste tradução/adaptação, Walter Benjamin, contrariando a ideia de literalidade, considerava impossível uma teoria da imitação num processo de tradução, pois tanto a língua fonte quanto a língua meta possuem formas diferentes de entender a realidade e de representa-la por meio da escrita, e que por isso, no processo de conhecimento (tradução), não deve haver objetividade (BENJAMIN, 2013, p. 107. Parênteses nossos). Haroldo de Campos segue esta mesma linha de pensamento, mas vai um pouco mais além, e diz que "Traduzir é reinventar" (CAMPOS, 2011, p. 13).

Apesar de Silva Mendes não considerar sua obra como uma tradução ou mesmo adaptação, possivelmente por falta de conhecimentos teóricos desta área, se levarmos em consideração as definições feitas anteriormente, bem como a ideia de impossibilidade de imitação e da tradução como reinvenção, e juntando a proposta do autor de apresentar o Taoismo aos portugueses de uma forma mais compreensível, Excerptos de Filosofia Taoista pode sim ser considerado uma reescrita, não exatamente uma tradução ao pé da letra, como aquelas criticadas pelo autor, pois fica claro que não se trata de uma tradução palavra-a-palavra, mas

7 Para saber mais sobre teorias da adaptação, ver: HUTCHEON, Linda. A Theory of Adaptation. New York: Routledge, 2006. 
uma adaptação de alguns trechos das duas obras clássicas chinesas, feita com o objetivo de popularizar o pensamento taoista e facilitar a interpretação de alguns de seus conceitos.

\section{Mecanismos de adaptação utilizados por Silva Mendes}

Para tentar sanar o problema de incompatibilidade entre o idioma original e o português, Silva Mendes se utiliza de alguns mecanismos textuais que considera facilitadores do entendimento dos textos. Um deles é a escrita em verso, que, segundo sua opinião, seria "[...] mais própria para incitamento da leitura." (MENDES, 1963, p. 276). Para a realização deste procedimento, utiliza-se de estruturas poemáticas populares, como a redondilha maior e os versos decassílabos, a fim de produzir um ritmo agradável e de fácil assimilação. Como a intenção é a da facilitação interpretativa, seus poemas possuem uma linguagem muito clara, evitando qualquer tipo de hermetismo linguístico, tão próprio em obras de poesia.

Outro mecanismo são os conteúdos extras que o autor traz em sua reescrita, como explicações históricas e culturais de determinadas situações e personagens, informações estas que são escritas em meio aos poemas em vez de em notas de roda pé, como seria o mais comum. Considerando que o objetivo da obra é facilitar a compreensão dos conceitos apresentados nos textos originais, talvez estas informações adicionais em meio aos próprios poemas sejam para deixar a leitura mais fluída, fazendo com que o leitor não necessite interrompe-la para buscar explicações nas notas de roda pé e só então voltar a ela, deixando-a, assim, quebrada e menos prazerosa.

Através destes processos, Silva Mendes espera levar alguns conceitos das duas obras clássicas chinesas aos leitores portugueses de forma que possam ser compreendidas, desempenhando assim seu papel social como tradutor/adaptador, descrito por John Milton em seu livro Tradução, Teoria e Prática: “[...] há frequentemente referências ao tradutor tendo um papel social, uma vez que ele promove o bem comum, proporcionando o acesso a trabalhos estrangeiros." (MILTON, 1998, p. 2), pois independente do rótulo que sua obra leve, o autor desempenhou uma façanha louvável apresentando estas duas obras tão importantes para a cultura chinesa em língua portuguesa numa época em que só se encontravam versões traduzidas para outras línguas estrangeiras, como o inglês, o francês e o alemão, que, apesar de serem consideradas boas traduções, apresentavam um texto ainda obscuro aos leitores que não entendiam cultura e história chinesa. 


\section{Explicações históricas em Chuang Tze e o rei de Chu}

Pare melhor exemplificar as questões vistas até agora, foi escolhido para análise um dos poemas da obra Excerptos de Filosofia Taoista chamado Chuang Tze e o rei de Chu, baseado num trecho do Nán Huá Jing de Zhuāngzǐ, e também o trecho original em chinês clássico bem como a tradução feita por James Legge do mesmo.

O trecho a ser analisado é muito famoso e conta o encontro de Zhuāngž̀ com dois oficiais do famoso rei de Chu, que vêm até ele a pedido do próprio rei para nomeá-lo ministro de estado. Este pequeno diálogo trata de princípios taoista fundamentais, como a não interferência do homem na natureza e a crítica às convenções sociais.

Comecemos pelo trecho original, seguido pela tradução de Legge, interpretação mais usual do texto e, por fim, o poema de Silva Mendes e a análise.

Versão original em chinês clássico:

莊子釣於誉水，楚王使大夫二人往先焉，曰：「願以境內累矣！」 莊子持竿不顧, 曰: 「吾聞楚有神龜, 死已三千歲矣, 王巾笥而藏之廟 堂之上。此龜者, 寧其死為留骨而貴乎, 寧其生而曳尾於塗中乎? 」二 大夫曰:「寧生而曳尾塗中。」莊子曰:「往矣！吾將曳尾於塗中。」 (ZHUĀNGZǏ, 1999, p. 280)

Tradução literal da versão original:

Zhuāngzǐ pescar no rio Pu, rei Chu enviar dois altos oficiais intenção convidar, dizer: "Desejar fazer dentro fronteira trabalhar pesado." Zhuāngzǐ segurar vara ignorar, dizer: "Eu ouvir Chu ter tartaruga divina, morrer já três mil anos, panos específicos urna bamboo, e guardar sobre templo imperial. Esta tartaruga, preferir sua morte deixar seus ossos e ser valorizada? Preferir viver arrastar cauda meio lama? Dois altos oficiais dizer: "Preferir viver arrastar cauda meio lama." Zhuāngžl dizer: "Ir para frente, eu dever arrastar cauda meio lama."

Tradução de James Legge:

Kwang-Tze (once) fishing in the river Phû, when the king of Kb̂े sent two great officers to him, with the message, "I wish to trouble you with the charge

8 Tradução feita com o intuito de demonstrar as peculiaridades do chinês clássico, como a falta de algumas preposições e a inexistência de conjugações verbais. 
of all within my territories," Kwang-Tze kept on holding his rod without looking round, and said, "I have heard that in Kbû, there is a spirit-like tortoise-shell, the wearer of which died 3000 years ago, and which the king keeps, in his ancestral temple, in a hamper covered with a cloth. Was it better for the tortoise to die, and leave its shell to be thus honoured? Or would it have been better for it to live, and keep on dragging its tail through the mud?" The two officers said, "It would have been better for it to live, and draw its tail after it over the mud". "Go your ways. I will keep on drawing my tail after me through the mud". (LEGGE, 1891, p. 390)

Neste trecho, a interpretação se mostra bem clara: Zhuāngzľ pescava tranquilamente quando veio a ele dois oficiais do rei de Chu indaga-lo se gostaria de se tornar um chefe de estado. O sábio, quase os ignorando, diz ter ouvido falar que o rei de Chu possui o cadáver de uma tartaruga morta há três mil anos, e que a guarda com muito cuidado no salão dos ancestrais e os pergunta se a tartaruga preferiria morrer para ser venerada, ou continuar viva, arrastando sua cauda na lama. Os oficiais naturalmente respondem que preferiria continuar viva. É então que o filósofo recusa o pedido dizendo aos oficiais que ele também prefere continuar a arrastar sua cauda na lama.

Com base na tradição taoista, que busca a harmonização com a natureza através na não-ação (wúméi 無為), podemos interpretar que Zhuāngž̌, sendo um sábio taoista e, por consequência, que valoriza as coisas como elas são na natureza, portanto sem apego às coisas mundanas, jamais poderia aceitar um convite para se tornar chefe ou dono de algo, pois, assim como a tartaruga deveria continuar vivendo como tal, ele também prefere seguir seu curso natural e viver livremente.

Se compararmos a versão original com a tradução de Legge, não é difícil perceber que há uma tentativa clara de se manter próximo ao texto original. Entretanto, o sinólogo tenta compensar o extremo sintetismo do chinês clássico, principalmente o fato de não haver tempos verbais nem algumas preposições, com as devidas conjugações e frases mais longas e indicativas, e isso também demonstra sua tentativa em deixar o texto mais coeso, deste modo, quase dobrando seu tamanho se comparado com o original.

Naturalmente que, como a proposta é a tradução em si, esta não é acompanhada de uma interpretação, ficando o texto, apesar de bem traduzido, ainda obscuro para os leitores ocidentais não familiarizados com o pensamento taoista. E é exatamente onde consiste a crítica de Silva Mendes.

Apesar de, num contexto geral, o trecho ser de fácil interpretação, algumas informações que podem ser consideradas essenciais para uma melhor compre- 
ensão não são dadas pelo texto original, e, em decorrência, por suas traduções, como por exemplo quem era o rei de Chu e qual a função exata da tartaruga. São justamente estas informações adicionais que Silva Mendes traz em sua adaptação em forma versificada:

\section{Chuang Tze e o Rei de Chu}

Estando Chuang a pescar

Nas margens do rio P'u,

Recebeu do rei de Chu

Uma carta de saudar.

De saudar, porém, não era

Tão sómente o conteúdo:

Assim fosse, não houvera,

Quando a leu, ficado mudo.

Era o rei de Chu dos reis

Da «justiça e da bondade»:

Um irmão da Irmandade

De Confúcio e mais das Leis.

\section{Chuang amava a Natureza}

$E$ as virtudes que nos deu;

Vivia em paz na simpleza,

Via a Tao nas leis do Céu.

Ora a carta que da côrte

Lhe trouxera um mandarim,

Do princípio até ao fim

Era em termos desta sorte:

«Do rei de Chu a Chuang muito saudar: «És em Meng o farol de tôda a China; «Em talento e em virtude és tu sem par; «E a Shun e a Wan excedes na doutrina, «Quanto passa, T'ai Shan uma colina, «Quanto excede a Tung 'T'ing o vasto mar. «Tais virtudes, tais dons e tal talento
«E mais partes em ti tão excelentes, «É da minha vontade e aprazimento «Torná-los inda mais resplandecentes. «E assim pois, desde já, por êste meio, «Meu ministro de Estado te nomeio».

Pensativo, Chuang cessou, Por instantes, seu labor.

Em seguida, ao portador

Da missiva assim falou:

Diz-se que o rei de Chu (não sei no certo)

Tem uma tartaruga embalsamada

No altar do seus maiores, morta há perto

De três mil anos?!

- Sim; e não há nada

Mais claro, firme e certo do que ler

Na carapaça o que há de acontecer.

- E a ti que te parece (atalhou Chuang):

Queria ela, se ouvida fosse, estar,

Como está, venerada sôbre o altar,

Ou andar arrastando, inteira e sã,

Como dantes, a cauda pela lama?

- Preferia, é bem claro, ao culto e fama

Que sempre, e com justiça, teve e tem,

Passear por êste mundo ainda viva.

- Dize então a teu amo que também

Chuang prefere a segunda alternativa. 
Na versão de Silva Mendes, os aspectos gerais permanecem, não sendo difícil perceber que o conteúdo do poema e do texto original se mantêm praticamente o mesmo. Entretanto, analisando mais detalhadamente as estrofes destacadas, percebemos haver alguns trechos adicionais que trazem explicações importantes para uma melhor compreensão do sentido do texto.

Começando pela terceira estrofe, onde nos é apresentado o rei de Chu:

\section{Era o rei de Chu dos reis \\ Da «justiça e da bondade»: \\ Um irmão da Irmandade \\ De Confúcio e mais das Leis.}

O rei de Chu foi um dos monarcas dos Sete Reinos que constituíam o território chinês na antiguidade e um estudioso seguidor dos ritos confucianos, dos quais Zhuāngzǐ era contra. Segundo o primeiro historiador chinês, Sīmă Qiān (司馬遷), o interesse do rei de Chu em Zhuāngž̌ realmente teria acontecido.?

Confúcio (551-479 a.C.) foi um pensador chinês cuja filosofia, de uma forma resumida, baseava-se no convívio social harmonioso através da prática dos ritos, que eram códigos de etiqueta e conduta. Pregava a ideia de que uma sociedade ideal só poderia ser alcançada através da educação. ${ }^{10}$ Apesar do povo chinês em geral considerar os pensamentos dos dois sábios complementares um ao outro, sempre houve uma clara rivalidade entre taoistas e confucianos desde a idade antiga. Não há menções sobre Confúcio no Dào Dé Jing de Lăož̀, mas há críticas à prática dos ritos, ponto alto do pensamento confuciano. Entretanto, já Zhuāngzǐ se utiliza do personagem de Confúcio em diversas passagens de seu Nán Huá Jing para fazer várias críticas à imposição do comportamento social, deixando clara sua atitude anticonfuciana.

As informações de que o rei de Chu era confuciano e amante das leis contrasta fortemente com a estrofe seguinte, onde Zhuāngzǐ é apresentado:

\section{Chuang amava a Natureza \\ $E$ as virtudes que nos deu;}

9 Chinese Text Project, 老子韓非列傳. Disponível em: < http://ctext.org/shiji/lao-zi-han-fei-liezhuan> Acesso em: 23/09/2015.

10 Para saber mais sobre Confúcio, ver: CONFÚCIO. Os Analectos. Tradução, comentários e notas de Giorgio Sinedino. São Paulo: Editora Unesp, 2012. 
Vivia em paz na simpleza,

Via a Tao nas leis do Céu.

Como praticante e propagador dos ensinamentos do Dào, Zhuāngzĩ não ligava para assuntos mundanos, e a única lei que seguia era a da natureza.

Diferentemente do texto original, onde o motivo da visita dos oficiais é explicada por eles mesmos, na versão de Silva Mendes é através de uma carta entregue por um mandarim. No conteúdo da carta, o próprio rei descreve e enaltece as qualidades de Zhuāngž̌, e, numa ingênua promessa de fama, como percebidos nos versos de sete a dez: "Tais virtudes, tais dons e tal talento / E mais partes em ti tão excelentes, / É da minha vontade e aprazimento / Torná-los inda mais resplandecentes.", tenta persuadir o sábio a se tornar um de seus ministros. Tal tentativa de persuasão se mostra completamente contraditória, visto que para o pensamento taoista, a verdadeira virtude não tem pretensões egoístas, pois o sábio que segue o Dào sempre se retira ao realizar algum feito e sua identidade é poucas vezes conhecida.

Ao passo que se lermos o trecho original ou mesmo suas traduções isoladamente, sem o conhecimento geral da obra, temos uma impressão de falta de respeito por parte de Zhuāngž̌, pois nem ao menos se vira para falar com os oficiais do rei, o poema de Silva Mendes nos traz os motivos que levaram a tal comportamento, pois fica evidente a contradição do rei de Chu, porque, mesmo demonstrando conhecer a fama do sábio, the faz um convite que vai totalmente contra a ideologia do pensamento taoista.

Como já dito anteriormente, no poema também é esclarecida a questão da tartaruga, onde na nona estrofe é dada a seguinte informação:

- Sim; e não bá nada

Mais claro, firme e certo do que ler

Na carapaça o que bá de acontecer.

A tartaruga é o símbolo da sabedoria ligada à paciência e longevidade. $\mathrm{Na}$ antiguidade clássica chinesa, seus cascos eram utilizados para a leitura do futuro, que era feita através da exposição ao calor e da interpretação das rachaduras causadas pelo aumento de temperatura. As carcaças muito antigas eram consideradas divinas, o que acarretava na crença de um poder de previsão ainda maior. 
Naturalmente que um chinês, ao ler o texto original ou mesmo uma tradução, entenderá perfeitamente a função e importância da tartaruga para a antiguidade clássica, mas para um leitor leigo em cultura e história chinesa, sem qualquer tipo de informação adicional é impossível compreender verdadeiramente o porquê da tartaruga no texto. Portanto, trazendo esta explicação à tona, Silva Mendes conduz o leitor a uma interpretação mais clara do motivo que levou Zhuāngž̌ a recusar o convite do rei de Chu. Como uma das características do Taoismo é a valorização daquilo que é natural, o fato do rei se utilizar de uma tartaruga morta para prever o futuro é completamente criticável para o pensamento taoista, uma vez que a tartaruga nasceu para ser apenas uma tartaruga, e não um oráculo, como Zhuāngžr nasceu para ser apenas Zhuāngž̆, e não um ministro de estado.

\section{Considerações Finais}

Linda Hutcheon em seu livro $A$ Theory of Adaptation explora as diversas possibilidades e processos pelos quais a adaptação pode ser feita. Para a autora, adaptar significa repetir sem replicar ${ }^{11}$, ou seja, retoma a ideia de que a adaptação é mais do que uma simples tradução, é um recontar através de processos necessários para adequar o texto fonte à mídia ou língua meta, considerando todas as diferenças culturais de um meio para o outro. Bastin, contrariando mais ainda o senso comum, diz que a adaptação é um procedimento que assegura a fidelidade à intenção comunicativa do texto original, pois esta não procura traduzir somente as palavras, principal objetivo de traduções ditas literais, mas também o significado e sentido do texto original, os quais estão muito além de uma mera equivalência de expressões (BASTIN, 1990 apud AMORIM, p. 86, 2005).

Levando em conta todas as citações e apontamentos feitos ao longo desta análise, e partindo das definições de Hutcheon (2006) e de Bastin (1990 apud AMORIM, 2005), o poema analisado pode, sim, ser considerado como uma adaptação ou reescrita do trecho do Nán Huá Jing, pois, apesar da diferença de linguagem e dos conteúdos adicionais, mantem uma clara intertextualidade com o texto original, mais que isso, o poema demonstra uma facilitação ao entendimento dos leitores portugueses leigos se comparada com traduções literais, voltadas para um público mais erudito, como a de Legge (1891), pois traz uma linguagem mais comum ao público em geral, além de um ritmo simples de leitura, ocasionado pela

11 HUTCHEON, 2006, p. 7. Vide bibliografia. 
escrita em verso, bem como informações histórico-culturais relevantes para uma melhor compreensão do texto.

Ainda há muito o que ser pesquisado nas obras de Manuel da Silva Mendes, e certamente há outras interpretações possíveis para seus Excerptos, ou mesmo para o poema analisado. Aqui, foi um pouco trabalhada a ideia de que o Excerptos de Filosofia Taoista pode ser considerado uma reescrita de alguns trechos dos livros Dào Dé Jing e Nán Huá Jing, e a análise discutiu o diálogo que o autor faz com a história e cultura chinesa no poema Chuang Tze e o rei de Chu, baseado na obra do escritor e pensador taoista chinês Zhuāngžr.

\section{Referências}

AMORIM, Lauro Maia. Tradução e Adaptação: Encruzilhadas da textualidade em Alice no País das Maravilhas, de Lewis Carrol, e Kim, de Rudyard Kipling. São Paulo: Editora UNESP, 2005.

ARESTA, António. "Manuel da Silva Mendes, Professor e Homem de Cultura". In: Revista de Administração Pública de Macau. Macau, 2002-4, n. 58, vol. XV.

BENJAMIN, Walter. "A Tarefa do Tradutor". In: Escritos sobre mito e linguagem. São Paulo: Editora 34, 2013.

CAMPOS, Haroldo de. Da transcriação poética e semiótica da operação tradutora. Belo Horizonte: Viva Voz, 2011.

CONFÚCIO. Os Analectos. Tradução, comentários e notas de Giorgio Sinedino. São Paulo: Editora Unesp, 2012.

CHENRG, Wu Jyh. Iniciação ao Taoismo. Rio de Janeiro: Mauad, 2000. V. 1.

HUTCHEON, Linda. A Theory of Adaptation. New York: Routledge, 2006.

KOHN, Livia. Daoism and Chinese Culture. St. Petersburg: Three Pines Press, 2012. $3^{\circ}$ Edition.

LAOZI. Dao De Jing [Tao Te King]. Tradução de Mario Bruno Sproviero. São Paulo:

LEGGE, James. The Sacred Books of China, the Texts of Taoism Part I. Oxford: Oxford University Press Warehouse, 1891.

MENDES, Manuel da Silva. Nova Coletânea de Artigos de Manuel da Silva Mendes Volume I. Macau: Folhetins de Notícias de Macau, 1963.

MILLER, James. Daoism: A Beginner's Guide. Oxford: Oneworld Publications, 2008.

MILTON, John. Traducão, Teoria e Prática. São Paulo: Martins Fontes, 1998.

ROBINET, Isabelle. Taoism: Growth of a Religion. Translated by Phyllis Brooks. Stanford: Stanforf University Press, 1997.

SCHIPPER, Kristofer. The Taoist Body. Translated by Karen C. Duval. California: University of California Press, 1993. 
VENUTI, Lawrence. The Translator's Invisibility: A bistory of translation. London and New York: Routledge, 1995.

ZHUĀNGZǏ. Zhuāngఇ̌̌l. 1 Edition. Hunan: Hunan People’s Publishing House, 1999. Library of Chinese Classics (Chinese-English). 